\title{
LA RESTITUCIÓN DE MENORES RETENIDOS ILÍCITAMENTE EN ESPAÑA Y LA EXCEPCIÓN DE GRAVE RIESGO A LA LUZ DE LA SENTENCIA DE LA AUDIENCIA PROVINCIAL DE BARCELONA DE 6 DE OCTUBRE DE 2020
}

\author{
THE RESTITUTION OF MINORS ILLICITLY RETAINED \\ IN SPAIN AND THE EXCEPTION OF SERIOUS RISK IN LIGHT \\ OF THE JUDGMENT OF THE PROVINCIAL HEARING \\ OF BARCELONA OF OCTOBER 6, 2020
}

\author{
Mercedes SABIDo Rodríguez \\ Profesora Titular de Derecho internacional privado \\ Universidad de Extremadura \\ ORCID ID: 0000-0003-1627-6725
}

Recibido: 15.06.2021 / Aceptado: 07.07.2021

DOI: https://doi.org/10.20318/cdt.2021.6269

\begin{abstract}
Resumen: El presente trabajo analiza, a la luz del litigio resuelto por la Audiencia Provincial de Barcelona, las cuestiones que suscita en la actualidad la sustracción internacional de menores. Las peculiaridades que estas situaciones presentan y, en particular, la vinculación con situaciones de violencia familiar, doméstica o de género, llevan a cuestionarnos la adecuación del sistema tradicionalmente instaurado en aras a la protección de los intereses del menor retenido ilícitamente. La alegación de grave riesgo como excepción a la restitución inmediata del menor requiere una práctica probatoria que, en ocasiones, es difícil conjugar con la instauración de un proceso ágil y rápido. Asimismo, en las circunstancias sanitarias actuales, es necesario articular mecanismos que permitan garantizar la tutela de los menores, auténticas víctimas de las sustracciones internacionales.

Palabras clave: sustracción de menores, traslado ilícito, retención ilícita, restitución del menor, excepción de grave riesgo.

Abstract: The present work analyzes, in the light of the litigation resolved by the Provincial Court of Barcelona, the issues that currently raises the international abduction of minors. The peculiarities that these situations present and, in particular, the connection with situations of family, domestic or gender violence, lead us to question the adequacy of the system traditionally established in order to protect the interests of the minor illegally detained. The allegation of serious risk as an exception to the immediate return of the minor requires an evidentiary practice that, at times, is difficult to combine with the establishment of an agile and fast process. Likewise, in the current health circumstances, it is necessary to articulate mechanisms that make it possible to guarantee the protection of minors, authentic victims of international abductions.
\end{abstract}

Keywords: Child abduction, wrongful removal, wrongful retention, return of the child, serious risk exception.

Sumario: I. Introducción. Particularidades de la sustracción internacional de menores en la actualidad. II. Hechos que dan origen a la Sentencia de la Audiencia Provincial de Barcelona de 6 de octubre de 2020. III. Mecanismos de tutela frente a traslados ilícitos de menores. 1. Intervención de 
Autoridades Centrales. 2. El proceso de restitución: objeto y características. IV. Excepciones a la restitución de menores trasladados ilícitamente. 1. El arraigo del menor. 2. La existencia de grave riesgo. Especial referencia a los supuestos de violencia doméstica. 3. La prueba en el marco del proceso de restitución. V. Las medidas de ejecución destinadas a garantizar el retorno. VI. A modo de conclusión.

\section{Introducción. Particularidades de la sustracción internacional de menores en la actualidad}

1. Han transcurrido más de cuarenta años desde la aprobación del Convenio de La Haya de 1980 sobre los aspectos civiles de la sustracción internacional de menores (en adelante, $\mathrm{CH} 80)^{1}$ y la sustracción internacional de menores continua siendo una realidad constante y un fenómeno creciente en nuestros días, favorecido por las circunstancias del mundo actual. La proliferación de relaciones familiares internacionales, la eliminación de las fronteras y el desarrollo de medios de comunicación facilita esta práctica ${ }^{2}$. Junto al $\mathrm{CH} 80$, y del mismo año, para hacer frente a los traslados ilícitos de menores las autoridades españolas también contaban con el Convenio europeo relativo al reconocimiento y ejecución de decisiones en materia de custodia de menores, así como al restablecimiento de dicha custodia ${ }^{3}$ y algún convenio bilateral ${ }^{4}$. A esta regulación convencional se añadió en 2003, en el marco de la Unión Europea, el Reglamento sobre competencia, reconocimiento y la ejecución de resoluciones judiciales en materia matrimonial y de responsabilidad parental (en adelante, Reglamento 2201/03) ${ }^{5}$ complementó la regulación del $\mathrm{CH} 80$ introduciendo algunas particularidades ${ }^{6}$.

2. La protección del interés superior del menor, verdadera víctima de los supuestos regulados, se configura como principio básico. Entre las manifestaciones de lo que constituye dicho interés se encuentran el derecho a no ser trasladado o retenido, a no ser apartado de su lugar de residencia habitual y el derecho a mantener el contacto y la relación del menor con ambos progenitores ${ }^{7}$. Junto al retorno o restitución inmediata del menor trasladado ilícitamente, y para garantizar su protección, la cooperación de autoridades se configura como eje central del sistema instaurado. En el Convenio, aquel principio sirve de fundamento para consagrar la restitución inmediata del menor como regla general a la vez que justifica la consagración de circunstancias que permiten excepcionar la obligación de retorno inmediato asumida por los Estados contratantes ${ }^{8}$. El texto europeo, que parte de la competencia de los tribunales

\footnotetext{
${ }^{1}$ Convenio sobre los aspectos civiles de la sustracción internacional de menores, hecho en La Haya el 25 de octubre de 1980 (BOE, núm. 202, de 24 de agosto de 1987).

2 A. L. Calvo Caravaca/J Carrascosa González, “Sustracción internacional de menores: una visión general”, en Y. GamaRRA CHOPo El discurso civilizador en Derecho internacional: cinco estudios y tres comentarios, 2011, pp. 115-155.

${ }^{3}$ Convenio europeo relativo al reconocimiento y ejecución de decisiones en materia de custodia de menores, así como al restablecimiento de dicha custodia hecho en Luxemburgo el 20 de mayo de 1980 (BOE núm. 210, de 1 de septiembre de 1984).

${ }^{4}$ Convenio entre el Reino de España y el Reino de Marruecos sobre asistencia judicial, reconocimiento y ejecución de resoluciones judiciales en materia de derecho de custodia y derecho de visita y devolución de menores (BOE de 24 de junio de 1997). Vid. M Moya Escudero, "El secuestro de menores" en Cuadernos de Derecho Judicial, núm. 8, 2002, A. RodríGueZ BENOT (Dir) La multiculturalidad: especial referencia al Islam, págs. 411-460.

${ }^{5}$ Reglamento de la Unión Europea 2201/2003, de 27 de noviembre de 2003, relativo a la competencia, el reconocimiento y la ejecución de resoluciones judiciales en materia matrimonial y de responsabilidad parental, que deroga el Reglamento CE no 1347/2000, (DO L núm. 338, de 23 de diciembre de 2003).

${ }^{6}$ I. LoRENTE Martínez, Sustracción internacional de menores. Estudio jurisprudencial, práctico y crítico, 2019, espec. pp. 198-220; M. Herranz Ballesteros, "El Reglamento (CE) núm. 2201/2003. Alcance de la reforma en materia de sustracción internacional de menores en el espacio judicial europeo", Aranzadi Civil, núm. 2, 2004, pp. 2065-2085; M. SABIDo RodrígueZ, "La sustracción internacional de menores en Derecho internacional privado español: Algunas novedades que introduce el Reglamento 2201/03", Anuario Facultad de Derecho, vol. XXII, 2004, pp. 307-320.

${ }^{7}$ El interés superior del menor está consagrado en nuestro ordenamiento de acuerdo con lo dispuesto en el artículo 39 de la Constitución Española y de los artículos 2 y 11.2 de la Ley Orgánica 1/1996 y la Ley 26/2015, de 28 de julio, de modificación del sistema de protección a la infancia y a la adolescencia. Asimismo, constituye un principio universal consagrado en los textos internacionales. En este marco, el artículo 3.1 de la Convención sobre los derechos del niño o el artículo 24 de la Carta de los Derechos Fundamentales de la Unión Europea. Vid., entre otras, las SSAP de Asturias de 12 de enero de 2021 (EDJ 2021/519114) y la de Pontevedra de 2 de mayo de 2019.

${ }^{8}$ Véase el Aptdo. 25 del Informe Explicativo del Convenio $n^{\circ}$ XVIII de la Conferencia de La Haya sobre los aspectos civiles de la sustracción de menores, de 25 de octubre de 1980, elaborado por la Profra. E. Pérez Vera (en adelante, Informe Explicativo) Consultado en https://assets.hcch.net/docs/43df3dd9-a2d5-406f-8fdc-80bc423cdd79.pdf
} 
del Estado de la residencia habitual del menor, atendiendo a dicho interés, también prevé, con carácter general, la restitución inmediata en los términos del CH80 y de su artículo 11. No obstante, en los Estados miembros de la Unión Europea las posibilidades de excepcionar la restitución se reducen si se demuestra que se han adoptado medidas adecuadas para garantizar la protección del menor tras su restitución. El principio de confianza mutua sirve también de fundamento al sistema instaurado9.

3. La cooperación entre autoridades judiciales y administrativas de los Estados Parte se configura como un instrumento fundamental del sistema establecido. A través de ella se pretende garantizar los objetivos básicos del convenio que se centran, de un lado, en el retorno inmediato del menor trasladado ilícitamente a su entorno habitual y, de otro, en el respeto efectivo a los derechos existentes en el Estado de residencia habitual del menor ${ }^{10}$. En este marco, el convenio recurre a las Autoridades Centrales a las que impone algunas obligaciones si bien para su cumplimento deben tenerse en cuenta las particularidades previstas en los distintos sistemas jurídicos nacionales. El mecanismo de cooperación a través de Autoridades centrales no impide, como prevé el artículo 29 del propio texto, que la persona cuyo derecho de custodia o visita ha sido lesionado pueda optar por interponer ante las autoridades competentes del Estado al que ha sido trasladado el menor la acción directa de restitución.

4. Ni el convenio ni el reglamento abordan la regulación de los mecanismos procesales limitándose, el texto convencional, a señalar la necesidad de que en cada Estado se recurra a procedimientos rápidos, temporalmente breves y ágiles, a través de los cuales se otorgue un tratamiento prioritario a las demandas de restitución o retorno ${ }^{11}$. Tanto el artículo 2 como el artículo 11.2 del CH80 caracterizan de este modo el instrumento procesal que los Estados deben utilizar para garantizar el retorno de los menores trasladados ilícitamente. Para dar cumplimiento a las previsiones contenidas en el texto convencional, se promueve el recurso en los Estados Parte a procedimientos rápidos y de urgencia. En nuestro ordenamiento, tras la reforma operada en $2015^{12}$, este procedimiento se encuentra específicamente regulado en los artículos 778 quater a 778 sexies LEC. El procedimiento instaurado es aplicable cuando el supuesto vincula a países participantes en el texto convencional o sean Estados miembros. Al margen de estos casos, procederá bien el recurso al procedimiento de exequatur regulado en los artículos 52 y siguientes de la Ley $29 / 2015$, de 30 de julio, de cooperación jurídica internacional en materia civil y mercantil bien el inicio de un procedimiento por parte del progenitor afectado en el país al que ha sido traslado el menor.

5. En la actualidad, las sustracciones internacionales de menores proyectan una realidad que las diferencia de aquellas que dieron lugar al nacimiento del texto convencional ${ }^{13}$. En sus orígenes, el CH80 responde a situaciones en las que los traslados de menores fuera de su entorno habitual eran realizados por el titular del derecho de visita y, generalmente, tenía por finalidad legalizar la nueva situación de hecho que tras el secuestro se creaba ${ }^{14}$. Los supuestos más recientes evidencian otra realidad. Ni el titular del derecho

\footnotetext{
${ }^{9}$ Vid. considerando 21 Reglamento 2201/03. M. P. Astray Chacón, "Las sombras del proceso de restitución del menor. El reto de la urgencia y eficacia. Buenas prácticas. Excepciones al retorno o restitución del menor. Especial referencia a supuestos de violencia de género o intrafamiliar", Cuadernos Digitales de Formación 15 - 2020, 1-92, espec. p. 47

${ }^{10}$ Vid. aptdo. 35 del Informe Explicativo

${ }^{11}$ Informe Explicativo, aptdo 104

${ }^{12}$ La Disposición Final tercera de la Ley 15/2015, de 2 de julio, de Jurisdicción Voluntaria, introdujo un nuevo Capítulo IV bis en el Título I del Libro IV de la Ley de Enjuiciamiento Civil, integrado por los artículos 778 quater a 778 sexies, en el que se contienen las medidas relativas a la restitución de menores en supuestos de sustracción internacional de menores; regulación que entró en vigor el 23 de julio de 2015.

${ }^{13}$ A.L. Calvo Caravaca/J. Carrascosa González, "Sustracción internacional de menores: una visión general (...)”, cit.

${ }^{14}$ Informe Explicativo, "el problema abordado por el Convenio -con todo lo dramático que conlleva el que se refiera directamente a la protección de la infancia en las relaciones internacionales adquiere toda su importancia jurídica por la posibilidad que tienen los particulares de establecer vínculos más o menos artificiales de competencia judicial. En efecto, por esta vía, el particular puede alterar la ley aplicable y lograr una resolución judicial que le sea favorable. Ciertamente, tal resolución, sobre todo cuando coexista con otras, dictadas por otras jurisdicciones, de contenido contradictorio, tendrá una validez geográficamente limitada pero, en cualquier caso, aportará un título jurídico suficiente para "legalizar" una situación de hecho que ninguno de los sistemas jurídicos afectados deseaba". Véase párrafos 12 a 15.
} 
de visita ni el padre suele ser quien traslada a los menores; es más, en muchos supuestos no existe pronunciamiento previo de fondo sobre la responsabilidad parental. Tampoco quien lleva a cabo la sustracción tiene como finalidad legalizar la situación de hecho creada tras el traslado ilícito. En un amplio número de casos, que aumenta considerablemente, la violencia doméstica y familiar está vinculada a la sustracción internacional de menores ${ }^{15}$. En algunos de ellos, es la madre, víctima de violencia doméstica, quien se marcha del país de residencia habitual y traslada a los niños con ella. La finalidad de la sustracción no es legalizar la situación de hecho creada sino "escapar" de la violencia doméstica a la que se encuentra sometida ella directamente y el menor, directa o indirectamente ${ }^{16}$. Frente a la acción de restitución o retorno, en este tipo de supuestos, la madre sustractora se opone alegando excepción de grave riesgo para el menor. Sin embargo, como tendremos ocasión de exponer a lo largo de este trabajo, a pesar del incremento de casos el análisis de la realidad evidencia que en pocas ocasiones es admitida esta alegación.

6. A partir del cambio en las circunstancias fácticas, se ha cuestionado la virtualidad de las soluciones y mecanismos tradicionalmente adoptados para resolver los supuestos de sustracción internacional de menores ${ }^{17}$. Se ha debatido su adecuación a la tutela del interés superior del menor y, en general, a la protección de los derechos de los menores ${ }^{18}$. Se plantea si la restitución inmediata de los menores trasladados ilícitamente continua siendo la solución más adecuada en supuestos como los descritos, en los que se alega algunas de las causas de excepción al retorno previstas en el texto convencional. La restitución inmediata no puede ser una decisión automática sino el resultado de una valoración de la prueba realizada en un proceso con todas las garantías. Sin embargo, frente a la rapidez y urgencia de la tramitación del proceso de restitución se ha cuestionado su adecuación en aquellos casos en los que se invoca la excepción de grave riesgo para el menor derivada de una situación de violencia doméstica. La jurisprudencia del TEDH ha evidenciado, en reiteradas ocasiones, esta problemática señalando la vinculación entre los derechos de los menores y el proceso civil ${ }^{19}$.

7. En esta línea, con el fin de reforzar la tutela del interés superior del menor al adoptar las resoluciones de restitución, las iniciativas europeas han promovido la reforma del Reglamento 2201/0320 dando lugar a la reciente aprobación del nuevo Reglamento 2019/111121. En el marco de la Conferencia

\footnotetext{
${ }^{15}$ Haciéndose eco de esta realidad, la expresión utilizada en el Doc prel. Núm. 6 de julio de 2017. Tabla de Conclusiones y Recomendaciones de las Reuniones anteriores de la Comisión Especial (CE) sobre el Convenio de 1980 sobre Sustracción Internacional de Niños y el Convenio de 1996 sobre Protección de Niños (1989 (1 $\left.{ }^{\mathrm{a}} \mathrm{CE}\right), 1993$ (2 $\left.{ }^{\mathrm{a}} \mathrm{CE}\right), \mathrm{CE} 1997$ (3 $\left.{ }^{\mathrm{a}} \mathrm{CE}\right), \mathrm{CE} 2001$ (4 $\left.{ }^{\mathrm{a}} \mathrm{CE}\right)$, CE 2002 (continuación CE), CE 2006 (5 CE), CE 2011-CE 2012 (6 $\left.6^{\mathrm{a}} \mathrm{CE}\right)$ ) en https://assets.hcch.net/docs/750ac1e59709-4d98-b5b3-f7f75639f135.pdf

${ }^{16}$ I. ReIG FABADO, "El traslado ilícito de menores en la UE. Retorno vs. Violencia familiar o Doméstica”, CDT, (marzo 2018) vol.10 núm.1, pp. 610-619; M. J. CAÑAdAs LoREnzo, "La incidencia de la violencia de género en la sustracción internacional de menores" en Jornadas de Unificación de Criterios en materia de Violencia de Género, celebradas en Madrid en octubre de 2017. Disponible en http:/www.poderjudicial.es/cgpj/es/Temas/Violencia-domestica-y-degenero/ Actividad-del-Observatorio/ Formacion/Jornadas-Unificacion-de-criterios-enmateria-de-Violencia-de-Genero--4-al-6-de-octubre-de-2017; M. V. CUARTERO RuBio, "La alegación de violencia doméstica en el proceso de restitución internacional de menores", en M. T. MARTín LóPEz/J. M. Velasco Retamosa (Coord.) La igualdad de género desde la perspectiva social, jurídica y económica, 2014, pp. 74-101; M. Requejo Isidro, "Secuestro de menores y violencia de género en la Unión Europea", Anuario Español de Derecho Internacional Privado, vol. 6, 2006, pp. 179-194; M. EsLaVA Rodríguez, "Secuestro internacional de menores y violencia doméstica", Manuales de formación continuada, núm. 25, 2004, pp. 131-182.

${ }^{17}$ A. L. Calvo Caravaca/J: Carrascosa González, Convenio de La Haya de 25 de octubre de 1980 y sustracción internacional de menores: algunas cuestiones controvertidas, en E. Pérez Vera/J.C. Fernández Rozas/M. Guzmán Zapater/A. FerNÁNDEZ Pérez/M. GuZMÁn PeCEs (Dirs.) El derecho internacional privado entre la tradición y la innovación: libro homenaje al profesor doctor José María Espinar Vicente, 2020, pp. 185-205; E. RodRíguez PINEAU, "La oposición al retorno del menor secuestrado: movimientos en Bruselas y La Haya", REEI 2018 (35), www.reei.org.

${ }^{18}$ J.R. LIÉBANA ORTiz, "El nuevo proceso relativo a la sustracción internacional de menores”, REDUR 13, diciembre 2015, págs. 83-109.

${ }^{19}$ Vid SAP de Girona de 23 de enero de 2017 (EDJ 2017/46318) con cita de las SSTEDH de 22 junio 1989, Erikson contra Suecia y de 27 octubre 2011, Bergmman contra Republica Checa.

${ }^{20}$ Reglamento de la Unión Europea 2201/2003, de 27 de noviembre de 2003, relativo a la competencia, el reconocimiento y la ejecución de resoluciones judiciales en materia matrimonial y de responsabilidad parental, que deroga el Reglamento CE n 1347/2000, conocido como Bruselas II bis (DO L núm. 338, de 23 de diciembre de 2003).

${ }^{21}$ Reglamento de la Unión Europea 2019/1111, de 25 de junio de 2019, relativo a la competencia, el reconocimiento y la
} 
de La Haya, si bien no se consideró necesario la revisión del CH80, se ha elaborado la Guía de Buenas Prácticas con el fin de promover la coherencia en la aplicación e interpretación del texto convencional ${ }^{22}$.

8. La sentencia dictada por la Audiencia Provincial de Barcelona, de fecha 6 de octubre de $2020^{23}$, nos brinda la oportunidad de retomar el análisis de la problemática señalada y plantearnos la virtualidad de las soluciones tradicionalmente adoptadas para resolver los supuestos de sustracción internacional de menores atendiendo a la realidad en la que actualmente estas situaciones se producen y su adecuación en orden a la tutela del interés superior del menor y de sus derechos. Para abordar su análisis, tras esta introducción (I), y a partir de un breve resumen de los hechos de los que trae causa la decisión analizada (II), estructuraremos nuestro trabajo distinguiendo algunas de las cuestiones más relevantes puestas de relieve en la decisión de la Sala. En primer lugar, el proceso de restitución (III) a partir del marco normativo instaurado delimitaremos su objeto y principales características, distinguiéndolo de otros procesos que tienen por objeto la adopción de medidas de responsabilidad parental. En segundo lugar, centraremos nuestra atención en el análisis de la alegación de la excepción de grave riesgo (IV); en particular, delimitaremos su contenido (1) así como el análisis de algunas dificultades que, en orden a su prueba, se suscitan en la práctica judicial (2). En tercer lugar, haremos una referencia a la importancia que adquieren en este ámbito las medidas de ejecución de la orden de restitución (V), para terminar con la exposición de unas breves conclusiones (VI).

\section{Hechos que dan origen a la sentencia de la Audiencia Provincial Barcelona de 6 de octubre de 2020}

9. Tras residir unos años en distintas ciudades europeas, en 2018, la familia Gil fijó su residencia definitiva en Edimburgo. El sistema educativo y la posibilidad de asistencia de sus dos hijos, que contaban dos y cuatro años de edad respectivamente, a uno de los centros educativos de mayor prestigio en el país constituyeron elementos clave en la decisión adoptada. En junio de 2019 la Sra. Gil se traslada con sus hijos a España, sin consentimiento del progenitor y sin que este tuviera conocimiento del lugar donde se encontraban sus hijos hasta el mes de octubre, cuando la Sra. Gil informó al padre que tenía a sus hijos en Granollers. En ese momento, el Sr. Gil solicita ante las autoridades centrales del Estado de su residencia habitual el retorno de los menores.

10. La Autoridad Central española inicia expediente para valorar la petición de retorno que había recibido de la autoridad central escocesa en septiembre de 2019. En el ámbito de dicho expediente, según consta en la sentencia de instancia, se indicó por la Autoridad Central española que la progenitora se opuso a devolver a los menores y que mostraba síntomas de haber sido víctima de violencia de género por lo que no se brindaría asistencia legal y pública al solicitante del retorno, sin perjuicio de la posibilidad de reclamar ante los tribunales españoles de conformidad con lo dispuesto en el art. 29 CH80. Posteriormente, el padre de los menores interpone ante los tribunales españoles demanda de restitución inmediata de sus hijos interesando que se declare la ilicitud del traslado así como el retorno al lugar de procedencia, el cierre de las fronteras, la prohibición del territorio nacional y la entrega por la madre demandada de los pasaportes de los menores.

11. El tribunal de instancia, en sentencia de fecha 10 de julio, tras declarar la ilicitud del traslado ex artículo 3 del CH80 y a los efectos de resolver la demanda planteada, verifica si concurre la alegación

\footnotetext{
ejecución de resoluciones judiciales en materia matrimonial y de responsabilidad parental, y sobre la sustracción internacional de menores (DO L núm. 178, de 2 de julio de 2019).

${ }^{22}$ Véase los distintos contenidos que integran la Guía de Buenas Prácticas en virtud del Convenio de La Haya del 25 de octubre de 1980 sobre los aspectos civiles de la sustracción internacional de menores https://www.hcch.net/es/publicationsand-studies/publications2/guides-to-good-practice.

${ }^{23}$ SAP de Barcelona 8805/2020, de 6 de octubre (ECLI:ES:APB:2020:8805).
} 
invocada por la demandada, con base en el artículo 13 b) del texto convencional, relativa a la existencia del grave riesgo para los menores de sufrir peligro físico o psíquico si se lleva a cabo el retorno o restitución. Para ello, la decisión de instancia se refiere, de un lado, a la documental aportada con la contestación a la demanda. Se trata de notas de la Women's Aid Edimburgo. Sin embargo, por carecer de traducción ex art. 144 LEC, no pueden ser valoradas. La falta de denuncia, a pesar de acreditar la existencia de una relación muy conflictiva entre las partes no acredita la concurrencia de la causa invocada. La ilicitud del traslado y, por ende, el retorno de los menores es una medida necesaria y proporcional. En consecuencia, entiende el tribunal de instancia, que no concurre la causa invocada por la demandada y ordena la restitución inmediata de los menores a Edimburgo. Su decisión se fundamenta, a tenor de la prueba practicada, por quedar acreditado el arraigo de los menores con el país de origen, Edimburgo, sin que su estancia en España haya supuesto una desvinculación física y emocional con aquel; y, en segundo lugar, porque en ningún momento se ha acreditado que el progenitor demandante haya desarrollado comportamientos que coloquen a los menores en riesgo físico y psíquico.

12. Frente a esta decisión, la demandada en la instancia interpone recurso de apelación alegando error en la valoración de la prueba y cuestionando la residencia habitual y el arraigo de los menores en Edimburgo. Asimismo, en su escrito de impugnación el demandante en la instancia, ahora apelado, solicita la adopción de medidas de ejecución distintas a las acordadas para dar cumplimiento a la orden de restitución.

13. La SAP, tras delimitar el marco jurídico y el objeto del procedimiento relativo a la restitución del menor trasladado ilícitamente a España afirma que, no discutiéndose sobre la residencia habitual de los menores, el traslado ilícito trae como consecuencia la orden de restitución salvo que concurran las excepciones prevista en el CH80 y en el Reglamento 2201/03. Habiendo sido alegada una de estas excepciones por la demandada en la instancia, ahora apelante, la Sala se centra en determinar si concurre o no la causa prevista en el artículo 13 b) del texto convencional. Recurriendo a la interpretación ofrecida en el Informe Explicativo del CH80 y al Manual de Buenas Prácticas de la Conferencia de La Haya, a partir del análisis de la prueba practicada la Sala concluye la existencia de hechos producidos inmediatamente antes del traslado y con posterioridad en el contexto de una ruptura de pareja conflictiva pero que no se ha practicado prueba determinante para afirmar la existencia de grave riesgo físico o psíquico para los menores. En consecuencia, desestima el recurso y confirma la sentencia de instancia ordenando la restitución de los menores al Edimburgo. En cuanto al escrito de impugnación presentado por el demandante en la instancia, la SAP lo estima parcialmente adoptando medidas destinadas a garantizar la ejecución de la orden de restitución de los menores.

14. A partir de estos hechos, como señalábamos, el supuesto que analizamos evidencia las dificultades planteadas en los casos de sustracción internacional de menores para las que el CH80 y, en su caso, el Reglamento 2201/03, han constituido los instrumentos más eficaces en orden a garantizar la restitución inmediata del menor trasladado ilícitamente. Más allá de las tradicionales dificultades, el asunto revela las particularidades que proyecta la evolución de la realidad actual y que pueden llegar a cuestionar la virtualidad de las soluciones tradicionalmente adoptadas. Cuando los supuestos de sustracción internacional de menores están vinculados a situaciones de violencia doméstica, familiar o violencia de género los problemas se plantean en orden a determinar la subsunción de los mismos en el marco del artículo 13 b) del texto convencional así como en relación con la práctica probatoria, por las particularidades que este tipo de situaciones presenta. La búsqueda de soluciones adecuadas para la tutela del interés superior del menor requiere evitar el automatismo del retorno y, más allá del principio de confianza mutua entre Estados, evitar que el sistema se convierta en un instrumento favorable para quien ejercía la violencia permitiéndole ejercer control y presión sobre su víctima ${ }^{24}$. De otro lado, como tendremos ocasión de analizar más adelante, la situación excepcional de crisis sanitaria derivada

\footnotetext{
${ }^{24}$ C. Ruiz SutiL, "Implementación del Convenio de Estambul en la refundición del Reglamento Bruselas II Bis y su repercusión en la sustracción internacional de menores”, CDT, (octubre-2018), vol. 10, núm.2, pp. 615-641.
} 
de la declaración de pandemia mundial producida por el SARS-CoV-2 y, entre otras consecuencias, la declaración del estado de alarma y la imposibilidad de traspasar las fronteras ${ }^{25}$, perjudica a los menores haciendo necesaria la adopción de medidas tendentes a garantizar la tutela de sus intereses, asegurando el contacto con sus progenitores.

\section{Mecanismos de tutela frente al traslado ilícito de menores}

\section{La intervención de autoridades}

15. El CH 80 se configura como la piedra angular del sistema frente a los supuestos de sustracción internacional de menores. Se trata de un convenio de cooperación que, con el fin de evitar los traslados internacionales de menores, instaura un mecanismo de colaboración entre las autoridades judiciales y administrativas de los Estados contratantes en orden a la obtención de la restitución inmediata del menor a su entorno habitual. La cooperación se canaliza a través de las Autoridades Centrales creadas al efecto en cada Estado y se ha ampliado mediante la creación de la Red Internacional de Jueces de La Haya $^{26}$. No obstante, a tenor de lo dispuesto en el artículo 29 del texto convencional, este mecanismo no impide que la persona que sufre el desplazamiento del menor pueda ejercitar ante las autoridades competentes del Estado al que ha sido trasladado el menor una acción directa de restitución o de retorno. De hecho, en el litigio resuelto por la Audiencia de Barcelona ambas vías han sido utilizadas. De un lado, el Sr. Gil, en septiembre de 2019, cuando tuvo conocimiento del traslado de los menores a España, solicitó a las autoridades escocesas la restitución de los menores en el marco del texto convencional. Estas, en cumplimiento de las obligaciones impuestas en el artículo 7 CH80 comunicaron la solicitud a las autoridades españolas que, iniciaron el expediente pero, una vez conocieron que la progenitora se oponía a la restitución y que mostraba síntomas de haber sido víctima de violencia de género, no brinda asistencia legal y pública al solicitante, dejando abierta la opción de plantear ante nuestros tribunales la acción directa de restitución como así hizo el padre de los menores.

16. En el caso de España, la Autoridad Central es el Ministerio de Justicia y, en concreto, dichas funciones corresponden a la Subdirección General de Cooperación Jurídica Internacional, perteneciente a la Dirección General de Cooperación Jurídica Internacional y Derechos Humanos ${ }^{27}$. A partir de las previsiones convencionales, y de acuerdo con lo dispuesto en el apartado tercero del artículo 778 quater LEC, la Autoridad Central española encargada del cumplimiento de las obligaciones impuestas por el CH80 podrá promover el procedimiento de restitución. Cuando se admite la solicitud, la Autoridad Central actúa a través de los Abogados del Estado a los que remite el expediente junto con el escrito en el que se solicita la presentación de la demanda ante el juez competente y se expone brevemente el caso haciendo referencia a los documentos en los que se basa la pretensión y se señala la necesidad de ser informados del desarrollo del proceso con el fin de que la Autoridad Central pueda cumplir con sus obligaciones conforme al artículo 7 CH80. Cuando la solicitud proviene de un país europeo, se numeran expresamente los preceptos del Reglamento 2201/2003 aplicables y, en particular, se señala que no se

\footnotetext{
${ }^{25}$ Vid. Real Decreto 463/2020, de 14 de marzo, por el que se declara el estado de alarma para la gestión de la situación de crisis sanitaria ocasionada por el COVID-19 (BOE núm. 67, de 14 de marzo).

${ }^{26}$ Integrada por jueces designados por los Estados Parte, la creación de una Red Internacional de Jueces de La Haya especialistas en cuestiones de familia para que actúen como canales de comunicación y enlace con sus Autoridades Centrales nacionales, con otros jueces dentro de sus jurisdicciones y con los de otros Estados Parte, facilitando de este modo las comunicaciones y la cooperación y, en definitiva, asegurando la aplicación efectiva de los textos convencionales, especialmente, el CH80. Además de una función de comunicación general, los miembros de la Red desempeñan una segunda función de comunicación específica, que consiste en comunicaciones directas en supuestos concretos que favorece, atendiendo al interés superior del menor, el conocimiento recíproco de los distintos ordenamientos jurídicos, la confianza mutua y la resolución de los casos. Vid. https://assets.hcch.net/docs/3b5e76ee-b983-4bd6-89cd-680b678fcf37.pdf

${ }^{27}$ Véase, actualmente, el artículo 8 del RD 453/2020 de 10 de marzo, por el que se desarrolla la estructura orgánica básica del Ministerio de Justicia, y se modifica el Reglamento del Servicio Jurídico del Estado, aprobado por el Real Decreto 997/2003, de 25 de julio (BOE núm. 63, de 12 de marzo de 2020).
} 
podrá denegar la restitución de un menor basándose en lo dispuesto en la letra b) del artículo 13 CH80 si se demuestra que se han adoptado medidas adecuadas para garantizar la protección del menor tras su restitución, que se debe dar posibilidad de audiencia al solicitante y que el juzgado de origen tiene la última palabra. En todo caso, si el supuesto lo requiere para evitar que el menor sufra mayores daños, bien a petición de la autoridad central requirente o a juicio de la autoridad central española-requerida, se requiere al abogado que en su demanda solicite la adopción de medidas previstas en nuestra legislación ${ }^{28}$.

17. Cuando la Autoridad Central no admite la solicitud presentada, corresponde al solicitante, que ya no se beneficia de aquella representación, reclamar ante las autoridades españolas designando letrado y procurador al efecto. Es lo que ha ocurrido en el supuesto resuelto por la Audiencia Provincial de Barcelona. Esta actuación, lejos de favorecer una solución rápida de la situación en la que se encontraban los menores ha implicado una prolongación temporal de la misma y, en consecuencia, un perjuicio para los menores y una merma en aras a la consecución de los objetivos perseguidos en el texto convencional. Más aun cuando, coincidiendo con la declaración de la pandemia sanitaria derivada de la COVID 19, la estancia de los menores en España se ha prolongado durante más de un año. Sorprende, asimismo, no solo porque no es una actuación acorde con las previsiones convencionales sino porque tampoco es la actuación seguida tradicionalmente por la Autoridad Central española ${ }^{29}$. La tutela del interés superior de los menores requería resolver acerca de su restitución a la mayor brevedad posible $\mathrm{y}$, sin perjuicio de que dicha decisión debía ser acordada por las autoridades judiciales españolas, hubiera sido conveniente que la Autoridad Central española, conforme a lo previsto en la LEC, hubiera iniciado el procedimiento.

\section{El proceso de restitución: objeto y características}

18. De conformidad con el texto convencional, la solicitud ante las Autoridades Centrales no impide el ejercicio de la acción directa de restitución ante los tribunales del Estado al que ha sido trasladado el menor. Es lo que hizo el Sr. Gil ante la inactividad de las autoridades centrales españolas. No obstante, como hemos expuesto, el CH80 no aborda la tramitación del proceso de restitución, limitándose a señalar su objeto y cuáles son las notas que lo caracterizan, atendiendo a los objetivos y principios que lo rigen. Es más, tampoco establece una obligación para los Estados contratantes de adoptar un procedimiento específico a tal fin. Se limita a señalar la necesidad de recurrir, en cada Estado al procedimiento más rápido con el objetivo de proteger el interés del menor.

19. En España, sin embargo, atendiendo a las previsiones convencionales, se ha elaborado un procedimiento específico regulado en los artículos 778 quáter a 778 sexies LEC $^{30}$. Estos preceptos acogen un procedimiento rápido para resolver la solicitud de restitución frente a los supuestos de sustracción internacional de menores. La celeridad del procedimiento encuentra su fundamento en la necesidad de evitar el perjuicio que el paso del tiempo puede derivar en una resolución de hecho de la sustracción del menor y la vulneración de sus derechos ${ }^{31}$. De este modo, se establecen plazos muy breves para su tramitación así como mecanismos que facilitan las comunicaciones entre órganos y agilizan el proceso ${ }^{32}$.

\footnotetext{
${ }^{28}$ C. García Revuelta, “Aplicación práctica del Convenio de La Haya y el Reglamento 2201/03. El papel de la Autoridad Central”, http://www5.poderjudicial.es/CVsm/Ponencia_6_ES.pdf (última vez consultado el 1 de junio de 2021).

${ }^{29}$ Vid., entre otras, la SAP Girona de 23 enero de 2017 (EDJ 2017/46318).

${ }^{30}$ F. J. ForCada Miranda, "Carencias, necesidades y conflictos de la sustracción internacional de menores y el novedoso marco legal español”, REDI, vol. 68 (2016), 2, pp. 337-346; S. CALAZA LoPEZ, "El nuevo régimen jurídico de la sustracción internacional de menores". Diario La Ley, núm. 8564, 2015.

${ }^{31} \mathrm{La}$ jurisprudencia del TEDH ha puesto de relieve la merma que el paso del tiempo puede implicar para la tutela de los menores víctimas de sustracciones internacionales. Vid. M. P. Astray Chacón, "Las sombras del proceso de restitución del menor. (...)" cit, p 23.

${ }^{32}$ El artículo 778 quinquies LEC prevé un plazo de veinticuatro horas para la admisión de la demanda y un plazo máximo de tres días para que el Letrado de la Administración de Justicia requiera al progenitor sustractor para que comparezca y manifieste si accede a la restitución o retorno o se opone a esta. En esta misma línea, con el fin de facilitar las comunicaciones, el párrafo 7 del artículo 778 quater LEC faculta al juez para solicitar el auxilio de las autoridades centrales implicadas, de las
} 
Junto a la celeridad, otras notas que caracterizan el procedimiento instaurado son la especialización y la concentración. El conocimiento de los litigios sobre secuestro internacional de menores se atribuye, en los términos del artículo 778 quater LEC, atendiendo a criterios de proximidad y a la presencia del menor. Precisamente, aquella especialización y la vinculación actual entre estos supuestos y las situaciones de violencia familiar, doméstica o de género han servido para defender la competencia de los Juzgados de Violencia sobre la mujer en materia de sustracción internacional de menores ${ }^{33}$. Por último, el proceso instaurado potencia la mediación en orden a la resolución de controversias ${ }^{34}$.

20. El estudio de la sentencia dictada por la Audiencia Provincial de Barcelona nos permitirá valorar si la aplicación de este procedimiento garantiza la tutela del interés superior del menor. Esto es, si garantiza que el establecimiento de un proceso rápido y ágil no suponga una merma de los principios procesales y permita un análisis del supuesto en el que se valoren las circunstancias concurrentes entre las que se incluyen las excepciones alegadas por quien se opone a la solicitud de restitución. Para ello, el punto de partida lo constituye la delimitación del contenido y objeto del proceso de restitución, diferenciándolo, de otros procesos vinculados a la tutela de los intereses de menores.

21. A través del proceso de restitución o de retorno el órgano judicial se limita a decidir, a partir de la calificación del supuesto como traslado ilícito, si procede o no la restitución, esto es, la entrega del menor a la persona que lo ha reclamado, o, su retorno, el traslado del menor al Estado de residencia habitual anterior; y, en su caso, valorar la concurrencia o no de las excepciones alegadas por quien se opone a la demanda ${ }^{35}$. El tribunal que conoce del proceso de restitución no se pronunciará sobre el fondo de la custodia de los menores ni sobre cualquier otra medida relativa a la responsabilidad parental salvo que concurran alguna de las excepciones a la restitución o retorno. Esta delimitación material resulta claramente definida tanto en el artículo $16 \mathrm{CH} 80^{36}$ como en el sistema instaurado por el Reglamento 2201/03.

22. En este último caso, cuando la sustracción vincule a Estados miembros, de acuerdo con lo dispuesto en los artículos 10 y 11 del Reglamento 2201/03, los órganos judiciales del Estado miembro al que ha sido trasladado el menor decidirán acerca de su restitución o retorno ${ }^{37}$. En el supuesto de denegarlo, comunicarán su decisión a las autoridades del país de residencia habitual del menor anterior al traslado y si estas consideran que procede el retorno, su decisión sustituirá a aquella otra. Se distingue, de este modo, la competencia para conocer sobre el fondo, sobre la responsabilidad parental, que corresponde a los tribunales del Estado de la residencia habitual del menor y la competencia de los tribunales al que ha sido trasladado el menor que se trata de una competencia temporal para decidir únicamente acerca del retorno o la restitución ${ }^{38}$. Con ello se fortalece el principio de confianza mutua y la competencia de los tribunales de la residencia habitual del menor para conocer del fondo de la responsabilidad parental.

redes de cooperación judicial internacional existentes, de los miembros de la Red Internacional de Jueces de la Conferencia de La Haya y de los jueces de enlace.

${ }^{33}$ Vid. M. P. Astray Chacón, "Las sombras del proceso de restitución del menor. (...)”, cit. p. 29; M. J. Cañadas LorenZo, "La incidencia de la violencia de género en la sustracción (...)", cit., p. 3.

${ }^{34}$ F. J. ForCada Miranda, "El nuevo proceso español de restitución o retorno de menores en los supuestos de sustracción internacional: la decidida apuesta por la celeridad y la novedosa circular de la Fiscalía 6/2015 (Parte I)", Bitácora Millenium, núm. 3, 2016, p.2.

${ }^{35}$ Circular de la Fiscalía General del Estado 6/2015, de 17 de noviembre, sobre aspectos civiles de la sustracción de menores, pp. 65 y ss.

${ }^{36}$ Artículo $16 \mathrm{CH} 80$, las autoridades judiciales o administrativas del Estado contratante adonde haya sido trasladado el menor o donde está retenido ilícitamente, no decidirán sobre la cuestión de fondo de los derechos de custodia hasta que se haya determinado que no se reúnen las condiciones del presente Convenio para la restitución del menor o hasta que haya transcurrido un periodo de tiempo razonable sin que se haya presentado una demanda en virtud de este Convenio.

${ }^{37}$ Vid. la reciente STJUE, de 24 de marzo de 2021, as. Deutsche Lufthansa, C-603/20 PPU (ECLI: EU:C:2021:231).

${ }^{38}$ Vid. artículos 8, 10 y 12 del Reglamento 2201/03; Circular 2/2021, de 30 de abril, de la Fiscalía del Estado sobre el tratamiento de la competencia territorial en el orden civil (BOE núm. 120, de 20 de mayo) que se remite en esta materia a la Circular de la Fiscalía 6/2015, cit. pp. 51. 
23. En definitiva, tanto el $\mathrm{CH} 80$ como el Reglamento 2201/03 distinguen de un lado el proceso destinado a la restitución o el retorno al lugar de procedencia de los menores que hayan sido sustraídos ilícitamente, otorgando competencia para decidir sobre la demanda a las autoridades del Estado al que ha sido trasladado el menor; y, de otro, los procesos sobre el fondo de la custodia cuya competencia corresponde a los tribunales del Estado de la residencia habitual del menor.

24. En esta misma línea, respecto del proceso instaurado en la LEC, el Tribunal Constitucional ha afirmado que, respondiendo a los fines previstos en el CH80, "el ordenamiento español arbitra un procedimiento cuya duración no debería ser superior a seis semanas, que pretende, simplemente la restitución del menor trasladado ilegalmente, pero sin que la decisión adoptada en este procedimiento afecte al fondo de los derechos de custodia que sobre el menor puedan ostentarse. De ello se sigue que nos hallamos ante un procedimiento de tramitación urgente y de carácter sumario o provisional, ya que la resolución que se dicte no prejuzga los derechos de custodia sobre el menor, que deberán dilucidarse en otro proceso y por el Tribunal que resulte competente en cada caso ${ }^{39}$.

25. No obstante, la separación entre el proceso de restitución y otros procesos relativos o vinculados a la responsabilidad parental en ocasiones no resulta fácil. La interrelación entre el proceso de restitución y la posterior decisión sobre el fondo de la custodia es ineludible en muchos aspectos ${ }^{40}$. De un lado, el propio CH80, limitado a la ordenación de la restitución o retorno de menores, reconoce implícitamente la competencia judicial internacional de los tribunales del Estado de la residencia habitual del menor para conocer sobre el fondo de las medidas de responsabilidad parental. En el asunto analizado, tanto el JPI como la Sala afirman que la decisión sobre el fondo de la custodia corresponde al tribunal del Estado de la residencia habitual de los menores. De otra parte, esa interrelación se manifiesta en orden a valorar las excepciones alegadas por la parte que se opone a la restitución. El litigio resuelto por la Audiencia lo pone de relieve. La existencia de una relación conflictiva de pareja, acreditada en el marco de la excepción de grave riesgo para los menores ex artículo 13 b) CH80, es rechazada por tratarse, según manifiestan tanto el JPI como la AP, de una cuestión que debe valorar el tribunal de la residencia habitual anterior al traslado en el marco de un procedimiento que, relativo al divorcio y a la adopción de medidas en materia de responsabilidad parental, corresponda a tenor del Reglamento 2201/03 a referidos tribunales.

26. La solución, que encuentra su fundamento en el principio de confianza mutua, no responde a las necesidades que actualmente plantean los supuestos de secuestro internacional de menores ni a la tutela del interés superior del menor. Con independencia de que en un procedimiento posterior pueda resolverse acerca de la responsabilidad parental, en el marco del proceso de restitución procede determinar si existe o no riesgo para los menores atendiendo a las pruebas practicadas en relación con la alegación de grave riesgo efectuada por la parte ahora apelante, fundamentada en situaciones de violencia doméstica. Esto es, en el marco del proceso de restitución procede determinar si aquella relación conflictiva puede proyectarse sobre los menores afectándoles de tal modo que el retorno o la restitución supongan su exposición a un grave peligro físico o psíquico.

27. Delimitado así el objeto del proceso de restitución, la ilicitud del traslado constituye, en todo caso, el punto de partida ${ }^{41}$. Este se produce, a tenor al concepto previsto en los textos convencional y europeo, cuando el traslado se realice con infracción de un derecho de custodia atribuido con arreglo al Derecho del Estado en el que el menor tenía su residencia antes del traslado, bien por la legislación de dicho Estado bien por decisión judicial o administrativa bien por un acuerdo vigente, y se ejercía de forma efectiva, o se habría ejercido de no haberse producido el traslado. Se requiere, de un lado, la

\footnotetext{
${ }^{39}$ Vid. la STC 16/2016, de 1 de febrero, ECLI:ES:TC:2016:16. M. P. Astray ChaCóN, "Las sombras del proceso de restitución del menor. (...)", cit., p. 26

${ }^{40}$ Per omnia, vid, P. JimÉNEZ Blanco, "Litigios sobre la custodia y sustracción internacional de menores”, 2008.

${ }^{41}$ Entre otras, la SAP Pontevedra de 17 abril de 2018 (ECLI: ES:APPO:2018:354).
} 
existencia de un derecho de custodia, conforme al ordenamiento del Estado de la residencia habitual del menor; y, de otro lado, el ejercicio efectivo de ese derecho por su titular. No se exige, en consecuencia, la infracción de una resolución judicial sobre derechos de guarda y visita para declarar la ilicitud del traslado bastando modificar por la vía de hecho la situación del menor de tal modo que se produzca una alteración de sus relaciones con el progenitor no sustractor ${ }^{42}$.

28. En el supuesto que analizamos, tanto la sentencia recurrida como la de apelación califican el traslado de Edimburgo a España efectuado por la madre de los menores como traslado ilícito. No hay discusión, sin perjuicio de las consideraciones que más adelante expondremos sobre la alegación de arraigo efectuada por la apelante, sobre la residencia habitual de los menores en el momento de producirse el traslado -Edimburgo - ni sobre la titularidad de ambos progenitores de la responsabilidad parental. Tampoco se cuestiona la ausencia de consentimiento del progenitor a dicho traslado, ni es óbice para la declaración de la ilicitud del traslado el hecho de que no haya sido delimitada la responsabilidad parental. En consecuencia, el desplazamiento efectuado por la madre de los menores de Edimburgo a España es ilícito según el CH80 y el Reglamento 2201/03.

29. Verificada la existencia de un traslado ilícito, las autoridades españolas, en cumplimiento de las previsiones convencionales deben proceder a la restitución de los menores salvo que concurran algunas de las circunstancias excepcionales previstas en el convenio. El régimen instaurado, como hemos señalado, descansa en su totalidad en el rechazo unánime del fenómeno de los traslados ilícitos de menores y en la convicción de que el mejor método de combatirlos consiste en no reconocerles consecuencias jurídicas. Por ello la solución acogida es la restitución inmediata del menor. Ahora bien, este objetivo convencional debe estar siempre subordinado a la toma en consideración del interés del menor ${ }^{43}$, de ahí que, junto a aquella regla general el texto convencional consagre una serie de excepciones.

30. La autoridad del Estado requerido no estará obligada a ordenar la restitución del menor trasladado ilícitamente cuando la persona que se opone a la restitución acredite, conforme al párrafo primero del artículo del artículo 13, bien que "a) la persona, institución u organismo que se hubiera hecho cargo de la persona del menor no ejercía de modo efectivo el derecho de custodia en el momento en que fue trasladado o retenido o había consentido o posteriormente aceptado el traslado o retención; bien que b) existe un grave riesgo de que la restitución del menor lo exponga a un peligro grave físico o psíquico o que de cualquier otra manera ponga al menor en una situación intolerable. De otro lado, la autoridad competente podrá negarse a la restitución si comprueba que el menor se opone a ella cuando, atendiendo a su edad y grado de madurez, sea apropiado tener en cuenta sus opiniones. En ambos supuestos, las autoridades competentes del Estado requerido tendrán en cuenta la información proporcionada por la autoridad central o autoridades competentes del Estado de residencia habitual del menor en relación con la situación social del menor. En este marco excepcional, también debemos tener en cuenta las previsiones recogidas en el artículo 20 del mismo texto legal. En su virtud, es posible denegar la restitución del menor cuando no lo permitan los principios fundamentales del Estado requerido en materia de protección de los derechos humanos y de las libertades fundamentales ${ }^{44}$.

31. En el asunto resuelto por la Audiencia Provincial, la madre apelante se opone a la restitución de los menores alegando la existencia de "grave riesgo" en los términos del artículo 13 b) CH 80. Como excepción, su concurrencia no se presume sino que debe ser acreditada por quien la invoca. Corresponde a la Sala, por tanto, como autoridad judicial del Estado requerido, decidir si ordena o no la restitución

\footnotetext{
${ }^{42}$ Circular de la Fiscalía 6/2015, cit.; J. Martínez Clavo/M.J. SÁnchez Cano, "Estatuto jurídico del caso de Juana Rivas y Francesco Arcuri desde la perspectiva del Derecho internacional privado y del Derecho civil”, CDT (Marzo 2020), vol 12, núm. 1, pp. 728-762.

${ }^{43}$ Vid, entre otras, las sentencias de la AP de Asturias de 12 enero de 2021, n 1/2021 (ECLI: ES:APO:2021:104) y la de la AP de A Coruña de 5 julio de 2019 (EDJ 2019/660566).

${ }^{44}$ Véase el Aptdo. 30 del Informe Explicativo.
} 
del menor, no estando obligada a ello. Esta decisión se adoptará atendiendo a la prueba aportada por la parte que se opone a la restitución, parte ahora apelante, y a la información que sobre la situación social de los menores proporcionen las autoridades competentes de Edimburgo, Estado de residencia habitual de los menores. Aspecto que pasamos a analizar en el siguiente apartado.

\section{Excepciones a la restitución de los menores trasladados ilícitamente}

\section{El arraigo de los menores en España}

32. En su fundamento segundo, la sentencia de apelación concluye la existencia de un traslado ilícito. Para resolver tal calificación, la Sala atiende a la ausencia de discusión sobre la residencia habitual de los menores en el momento de producirse el traslado, sobre la titularidad de ambos progenitores de la responsabilidad parental y sobre el consentimiento del progenitor a dicho traslado. Procede, por tanto, la restitución salvo que concurran la circunstancia excepcional prevista en el artículo 13 b) CH80, a cuyo análisis dedicaremos el siguiente apartado, haciendo ahora una breve alusión a la alegación efectuada por la madre apelante relativa a que la residencia de los menores en Edimburgo fue de ocho meses y que aquellos tienen arraigo en España.

33. La relevancia de la residencia habitual de los menores resulta determinante en el ámbito de la protección de menores porque, como hemos expuesto, constituye un criterio básico del sector ${ }^{45}$. Su invocación por la apelante no se efectúa, por considerar que nos encontremos ante un litigio de responsabilidad parental sino por entender que, tratándose de un concepto fáctico, dicho lugar es España. Esta circunstancia desvirtuaría la calificación del supuesto en los términos del artículo 3 del CH80 $0^{46}$. Según consta acreditado en la sentencia apelada, después de residir en varias ciudades europeas, los menores han residido en Edimburgo solo ocho meses, donde fueron escolarizados. Posteriormente la madre los traslada a España donde han residido más de un año. El arraigo en España, aunque parece ser una cuestión planteada ex novo en la apelación, supone la integración de los menores en el Estado al que han sido trasladado. Ciertamente, desde que en junio de 2019 se produce el traslado ilícito hasta que en julio del 2020 se resuelve la restitución por el JPI transcurre más de un año. Este tiempo, sin duda, permite a los menores adaptarse e integrarse en España, su nuevo lugar de residencia. Este último país es el lugar donde más tiempo han pasado y podría acreditarse que se han adaptado y que en él han desarrollado su vida cotidiana.

34. Sin embargo, la prolongación de esta residencia es coyuntural. Aunque la ausencia de una definición legal de residencia habitual favorece el debate planteado por la apelante, a partir de la interpretación efectuada por el TJUE, la residencia habitual del menor en el marco del texto europeo se corresponde con el lugar en el que el menor, atendiendo a su duración, regularidad, condiciones y razones de su estancia, está integrado en un entorno social y familiar ${ }^{47}$. En el caso resuelto por la Audiencia, sin perjuicio de las consideraciones que expondremos, la prolongación de la estancia se ha producido por circunstancias extraordinarias. Además, como afirma la Sala en el fundamento quinto de su sentencia, el arraigo o en términos del art. 12 del Convenio de la Haya "integración en el nuevo ambiente" debe

\footnotetext{
${ }^{45}$ El considerando 12 del Reglamento 2201/03 prevé que "Las normas de competencia que establece el presente Reglamento en materia de responsabilidad parental están concebidas en función del interés superior del menor, y en particular en función del criterio de proximidad. Esto significa por lo tanto que son los órganos jurisdiccionales del Estado miembro en el cual el menor tiene su residencia habitual los que deben ser competentes en primer lugar,(..)". En esta misma línea se ha pronunciado el TJUE, entre otras, la sentencia de 15 de julio de 2010, Purrucker, C256/09, (EU:C:2010:437), apartado 91.

${ }^{46}$ Es la residencia habitual de la menor inmediatamente antes de la infracción de los derechos de custodia o de visita la que determinará la licitud o ilicitud del traslado. Vid. STJUE de 8 de junio de 2017, as. $O L$ y $P Q, \mathrm{C}-111 / 17$, (ECLI:EU:C:2017:436); 2 de abril de 2009, as. A, C-523/07, (ECLI:EU:C:2009:225) y 9 de octubre de 2014, as. $C y M$, C-376/14 PPU, (ECLI:EU:C:2014:2268).

${ }^{47}$ Entre otras, vid. SSTJUE de 2 de abril de 2009, as. A, C-523/07, (ECLI:EU:C:2009:225); de 22 de diciembre de 2010, as. B. Mercredi y R. Chaffe, C-497/10 PPU (ECLI:EU:C:2010:829); de 9 de octubre de 2014, as. C y M, C-376/14 PPU, (ECLI:EU:C:2014:2268); de 15 de febrero de 2017, as. W, Vy X, C-499/15, (ECLI:EU:C:2017:118)
} 
ser valorado cuando ha transcurrido más de un año desde que se produjo la sustracción hasta que se plantea la demanda. En el presente caso la demanda se presentó en marzo de 2020, no obstante, desde noviembre de 2019, un mes después de conocer el traslado de los menores, el padre solicitó a través de las autoridades centrales escocesas la petición de restitución a la autoridad central española, que la denegó. El precepto citado prevé que no habrá de estimarse la demanda de restitución en aquellos supuestos en los que ha transcurrido un año desde el traslado ilícito sin que se haya efectuado la reclamación y se acredite la integración del menor en el nuevo ambiente. Circunstancias que no concurren en el presente asunto. No obstante, también es cierto que en este caso debe tenerse en cuenta la excesiva prolongación del proceso en detrimento de la tutela de los menores.

35. El retraso en la tramitación del procedimiento se ha producido como consecuencia de la declaración del estado de alarma decretado por la situación excepcional de crisis sanitaria. La celeridad que requería el texto convencional y a la que responden las disposiciones recogidas en la LEC ha resultado alterada por la crisis sanitaria y ello, sin duda, ha supuesto un perjuicio para los menores que han prolongado su estancia en España, alejados de su entorno habitual. Aunque fueron circunstancias sobrevenidas y excepcionales, con independencia de la suspensión de plazos o del sistema establecido a los efectos del cómputo del tiempo de prolongación de la situación de crisis, la tutela del interés superior de los menores requería la adopción de medidas tendentes a evitar que los menores se integren en el Estado al que han sido trasladados ilícitamente y la situación de hecho se consolide ${ }^{48}$.

36. La Guía de herramientas para el Convenio HCCH sobre sustracción de niños de 1980 en tiempos de Covid-19 establece algunas pautas para mitigar el impacto que supone la situación sanitaria y eliminar los obstáculos creados por la pandemia en orden a garantizar el cumplimiento de los requisitos procesales previstos en el texto convencional y eliminar los obstáculos para la restitución rápida ${ }^{49}$. En esta línea, por ejemplo, se incluyen instrumentos tendentes a asegurar la restitución rápida y segura del niño al Estado de residencia habitual llevando a cabo el cumplimiento adecuado y oportuno de las obligaciones del CH80; centrarse en el niño en cada caso particular, en el contexto de la aplicación del CH80; explorar cuidadosamente las excepciones planteadas a la obligación de restituir al niño, por ejemplo, la relacionada con la existencia de un posible grave riesgo de daño al niño tras su retorno; asegurar el contacto continuo y adecuado entre padres e hijos, especialmente cuando las medidas adoptadas frente a la COVID-19 puedan significar un período prolongado de separación física entre ellos; considerar la aplicabilidad de otras disposiciones en orden a la adopción de medidas provisionales urgentes para la protección del niño en espera de una solicitud de restitución; aprovechar la tecnología de la información, electrónica y de las comunicaciones, cuando sea posible, para asegurar que los casos previstos en el CH80 avancen hacia su resolución, incluyendo el archivo electrónico de documentos, las audiencias virtuales y/o híbridas, y la obtención de pruebas por medios electrónicos, entre otras.

37. En esta línea, con base en el foro previsto en el artículo 20.2 Reglamento 2201/03, hubiera sido conveniente la adopción de medidas destinadas a garantizar las relaciones de los menores con sus progenitores. Esta posibilidad, también estaría prevista en aquellos supuestos en los que no resulte aplicable el texto europeo y sean subsumibles en el ámbito de aplicación del Convenio de la Haya de 1996 relativo a la competencia, la ley aplicable, el reconocimiento, la ejecución y la cooperación en materia d responsabilidad parental y de medidas de protección de los niños ${ }^{50}$, conforme a lo previsto en su artículo 11. Conforme a estas disposiciones, los tribunales españoles, en tanto que tribunales que conocen del

\footnotetext{
${ }^{48}$ Sobre las cuestiones interpretativas que suscita el cómputo del plazo previsto en el CH80 y el principio del interés superior del menor, vid. C. I. CORDERO ÁlVAREZ, "Sustracción internacional de menores extracomunitaria: a vueltas con la obligación de restitución automática del Convenio de La Haya de 1980 en la práctica española”, CDT (marzo 2021), vol 13, núm. 1, pp. 134-152.

${ }^{49}$ Vid. https://assets.hcch.net/docs/3a0aceaf-a251-4eaa-a42c-4bbc227cd863.pdf

${ }^{50}$ Convenio relativo a la competencia, la ley aplicable, el reconocimiento, la ejecución y la cooperación en materia d responsabilidad parental y de medidas de protección de los niños, hecho en La Haya el 19 de octubre de 1996 (BOE núm. 291, de 2 de diciembre de 2010).
} 
traslado, gozan de competencia para adoptar las medidas cautelares previstas en su propia legislación ${ }^{51}$. En su virtud, a partir de las previsiones contenidas en los artículos 773 LEC y $158 \mathrm{Cc}$ el juez, a instancia de parte o de oficio, puede adoptar las medidas necesarias para la protección de los intereses del menor ${ }^{52}$.

38. En todo caso, siendo la protección de los menores la prioridad en supuestos como el que analizamos, las particularidades que el mismo plantea obliga a adecuar la solución convencional a la realidad regulada. El transcurso del tiempo favorece la adaptación de los menores en perjuicio de la restitución inmediata como medida más adecuada. En este marco, como afirmara el Tribunal Constitucional, la integración del menor constituye un elemento de ponderación imprescindible en relación con el objeto y fin del Convenio y de conformidad con sus previsiones, por lo que su valoración es esencial, cuando se trata del procedimiento de inmediata restitución ${ }^{53}$. No obstante, se proyectan en este punto las limitaciones del objeto y contenido del proceso de restitución y su diferenciación respecto del proceso sobre la responsabilidad parental a las que hemos hecho referencia. Como ha señalado la doctrina ${ }^{54}$, no concurriendo las exigencias previstas en el CH80 para admitir la excepción de arraigo en los términos del artículo 13 a) del texto convencional en la medida en que no ha transcurrido un período superior a un año desde el traslado y la fecha de inicio del procedimiento de restitución, no es posible excepcionar con base en dicha alegación la restitución solicitada.

\section{La existencia de grave riesgo. Especial referencia a los supuestos de violencia doméstica}

39. Frente a la demanda de restitución interpuesta por el Sr. Gil, la Sra Gil, ahora apelante, alega la excepción de la existencia de un grave riesgo de que la restitución exponga a los menores a un peligro físico o psíquico. La concurrencia de esta causa, en tanto que constituye una excepción a la regla general de restitución, debe ser acreditada por la parte que la alega ${ }^{55}$. A la Sra. Gil, a tenor de las previsiones normativas, corresponde su prueba. Debiendo ser valorada por el tribunal, conforme a las previsiones contenidas en el artículo 217 LEC, para decidir acerca de la restitución de los menores. Valoración en la que se centra el fundamento cuarto de la sentencia que analizamos.

40. La interpretación del grave riesgo, en tanto que excepción a la regla general de restitución o retorno inmediatos, debe realizarse de forma restrictiva. En este marco, el riesgo ha de ser grave y concreto, sin que sea posible invocar un riesgo genérico ${ }^{56}$. Además, el tribunal, para decidir sobre la con-

${ }^{51}$ SSTJUE de 2 de abril de 2009, as. A, C-523/07 (ECLI:EU:C:2009:225); de 23 de diciembre de 2009, as. J. Deticek y M Sgueglia, C-403/09 PPU (ECLI:EU:C:2009:810); de 15 de julio de 2010, as. B. Purrucker y G. Vallés Pérez, C-256/09 (ECLI:EU:C:2010:437).

${ }^{52}$ M. P. Astray Chacón, "Las sombras del proceso de restitución del menor. (...)” cit, p. 30.

${ }^{53}$ STC (Sala Segunda) de 1 de febrero de 2016 (RTC\2016\16).

${ }^{54}$ C. M. CAAmiÑa Domínguez, "El interés superior del menor: La integración en el nuevo menor", CDT, (Octubre 2016), Vol. 8, № 2, pp. 77-91; F. J. Forcada Miranda, "CARENCIAS, NECESIDADES Y CONFLictos DE LA SUSTRACCIÓN INTERNACIONAL DE MENORES (...) CIT. pp. 337-346.

${ }^{55}$ Vid., entre otras, el Auto de la AP Guipúzcoa de 14 septiembre de 2005 (ECLI: ES:APSS:2005:700A); las Sentencias de la AP de Barcelona, de 13 de marzo de 2012 (ECLI:ES:APB:2012:2580A); de la AP Baleares de 9 mayo de 2016, ${ }^{\circ}$ 141/2016, (ECLI: ES:APIB:2016:751); de la AP Girona de 23 enero de 2017, núm. 20/2017 (ECLI: ES:APGI:2017:15); de la AP Navarra de 3 octubre de 2018 núm. 449/2018 (ECLI: ES:APNA:2018:875); de la AP A Coruña, de 5 de julio de 2019, nº 262/2019, (ECLI: ES:APC:2019:1546); de la AP Madrid de 29 julio de 2020 (ECLI: ES:APM:2020:8521); de la AP de Málaga de 4 de noviembre de 2020 (ECLI:ES:APMA:2020:2464); de la AP de Barcelona de 12 de junio de 2020 (ECLI:ES:APB:2020:4886); de la AP Asturias de 12 enero de 2021, nº 1/2021 (ECLI: ES:APO:2021:104). En esta misma línea se pronuncia la Circular de la Fiscalía General del Estado 6/2015, cit.

${ }^{56}$ Entre otras, la SAP de Guipúzcoa de 5 marzo de 2020 (EDJ 2020/826643); la de Pontevedra de 2 de mayo de 2019 (ECLI: ES:APPO:2018:354), en la que la Sala manifiesta que esta excepción debe ser objeto de interpretación restrictiva y probada por quien la alega, alejada del mero concepto de conveniencia; la SAP de Santa Cruz de Tenerife (Secc. $1^{\text {a }}$ ) de 10 de mayo de 2018 afirma que es necesaria una certeza corroborada por pruebas objetivas del peligro físico o psíquico para las menores. Y en la SAP de Navarra (Secc. 3a) de 3 de octubre de 2018 (ECLI: ES:APNA:2018:875) se afirma que para que no proceda el retorno del menor se exige en primer lugar que exista un grave riesgo, no bastando un riesgo de carácter general y ambiguo, no determinado, y en segundo lugar que dicho riesgo conlleve la exposición del menor a un peligro físico o psíquico. 
currencia de la excepción planteada debe siempre basarse, a tenor de las circunstancias que singularizan el supuesto planteado, en el beneficio del interés superior del menor trasladado ilícitamente ${ }^{57}$. Con ello se trata de evitar, como señala el Informe explicativo, que el texto convencional se convierta en papel mojado. De otro modo, su invocación sistemática podría conllevar que los tribunales del lugar al que ha sido trasladado el menor sustituyan a los del Estado de su residencia habitual, con el menoscabo que ello implicaría al principio de confianza mutua que inspira el texto convencional ${ }^{58}$.

41. La autoridad competente para valorar la alegación de grave riesgo debe evaluar no solo las circunstancias anteriores al traslado sino, particularmente, la situación en la que se encontrará el menor al regresar a su Estado de residencia habitual; esto es, las circunstancias que tendrá si es restituido inmediatamente. Esta evaluación deberá comprender una valoración de las pruebas presentadas y acreditativas del riesgo alegado por quien solicita la no restitución, generalmente relacionadas con circunstancias anteriores o producidas en el momento del traslado. Asimismo, en función del peligro invocado, en su valoración el tribunal deberá tener en cuenta la existencia o no de medidas de protección adecuadas en el Estado de residencia habitual del menor. Para ello, junto a la actividad probatoria de quien solicita la restitución, el tribunal puede utilizar las vías articuladas a través de la cooperación judicial y cooperación de autoridades ${ }^{59}$. Este análisis le permitirá decidir si las circunstancias en las que el niño se pudiera encontrar supondrán o no su exposición a un grave peligro y, atendiendo a ello, concluir la restitución o no del menor trasladado ilícitamente.

42. La excepción de grave riesgo engloba distintas situaciones. De un lado, la exposición del niño a daño físico; de otro, la exposición del niño a daño psicológico; así como cualquier situación que ponga al niño en una situación intolerable ${ }^{60}$. Invocados de forma autónoma o en conjunto, estos riesgos se basan "en el interés primario de toda persona a no ser expuesta a un peligro grave físico o psíquico o colocada en una situación intolerable" ${ }^{61}$. A partir de esta delimitación, la primera cuestión que suscitan los supuestos de sustracción internacional de menores vinculados a situaciones de violencia doméstica o familiar se refiere a determinar si la alegación de violencia de género sobre la progenitora que efectuó el traslado, aunque no se hubiera producido contra los hijos, integra la causa de excepción antes referida, por cuanto los hijos pueden considerarse víctimas indirectas de la violencia de género ejercida contra su progenitora. En este punto debe tenerse en cuenta que España es parte del Convenio de Estambul sobre prevención y lucha contra la violencia contra las mujeres y la violencia doméstica ${ }^{62}$. Dicho texto acoge una noción amplia del concepto de violencia contra la mujer por razones de género en su artículo $3 \mathrm{~d}$ ) la define como "toda violencia contra una mujer porque es una mujer o que afecte a las mujeres de manera desproporcionada" $"$.

43. A partir de este concepto, su incidencia en los supuestos de sustracción internacional de menores se puede proyectar de distintas formas. De un lado, cuando el padre, agresor, traslada ilícitamente al menor ejerciendo así una forma de maltrato psicológico sobre la madre (supuesto de violencia vica-

${ }^{57}$ Véase, entre otras, la SSAP de Asturias de 12 de enero de 2021 (EDJ 2021/519114); la de Guipúzcoa de 5 marzo de 2020 (EDJ 2020/826643); la de A Coruña de 5 julio de 2019 (EDJ 2019/660566). J.J. CASTELLÓ PASTOR, "Excepciones legales al retorno del menor en los supuestos de sustracción internacional”, CDT, (marzo 2018), vol. 10, núm. 1, pp. 561-567.

${ }^{58}$ Véase el apartado 34 del Informe explicativo

${ }^{59}$ Véase apartado 43 de la Guía de Buenas Prácticas.

${ }^{60}$ Véase apartado 43 de la Guía de Buenas Prácticas.

${ }^{61}$ Véase el apartado 29 del Informe explicativo.

${ }^{62}$ Convenio de Estambul, de 11 de mayo de 2011, sobre prevención y lucha contra la violencia contra las mujeres y la violencia doméstica (BOE núm. 137, de 6 de junio de 2014).

${ }^{63}$ A diferencia del concepto más restringido previsto en la legislación española referido a aquella violencia que, como manifestación de situación de desigualdad y las relaciones de poder de los hombres sobre las mujeres, se ejerce sobre estas por un varón con el que tiene o ha tenido una relación conyugal o relaciones similares de afectividad (artículo 1 LO 1/2004, de 28 de diciembre, de medidas de protección integral contra la violencia de género). No obstante, de acuerdo con el Disposición Final Décima de la LO 8/2021, de 4 de junio, de protección a la infancia y la adolescencia frente a la violencia (BOE núm. 134, de 5 de junio), a partir de su entrada en vigor el próximo día 25 de junio, la violencia de género también comprende la violencia que con el objetivo de causar perjuicio o daño a las mujeres se ejerza sobre sus familiares y allegados menores de edad. 
ria); de otro lado, cuando la madre, víctima de violencia y para escapar de su agresor se traslada a otro Estado llevándose a sus hijos con ella; y un tercer caso, cuando el traslado de una hija menor se lleva a cabo para evitar que sobre ella se ejerza directamente violencia de género ${ }^{64}$. Si bien en este último supuesto la menor es víctima directa de la violencia no ocurre lo mismo en los dos primeros. Estando acreditada, no se cuestionará el grave riesgo que para un menor supone el retorno a la situación de violencia que sobre él se ejercía. Mayores dificultades plantean aquellos supuestos en los que los menores no son víctimas directas del daño sino indirectas. Tales situaciones implican que los menores vivan y crezcan en un entorno familiar conflictivo que supondrá un condicionante para su desarrollo y bienestar y causará serios problemas de salud, exponiéndolos a asimilar y normalizar tales conductas. En definitiva, como se pone de relieve en la Guía de Buenas prácticas ${ }^{65}$, la situación del progenitor que sustrae al menor para escapar de la violencia de la que es víctima sí puede afectar al menor. En tales supuestos, si la madre sustractora prueba la existencia de situación de grave riesgo para el menor en caso de regresar al Estado de residencia habitual, se configura la excepción de grave riesgo del artículo 13 b) del texto convencional.

44. La prueba en el proceso de restitución, por las limitaciones de su objeto, es más difícilib. Es lo que ocurre en el supuesto resuelto por la Audiencia. La Sra Gil alega que existe un grave riesgo para los menores atendiendo a las circunstancias de violencia doméstica sufridas durante su estancia en Edimburgo. A partir del análisis de la prueba practicada, entre otras el Informe del Centre per a la igualtat i recursos per a dones (CIRD) del Ayuntamiento así como conversaciones y mensajes, ha quedado acreditada la existencia de una relación muy conflictiva entre las partes litigantes. Como afirma la Sala, la prueba practicada acredita la existencia de hechos producidos inmediatamente antes del traslado y con posterioridad en el contexto de una ruptura de pareja conflictiva. No obstante, también se afirma que no se ha practicado prueba determinante para afirmar la existencia de grave riesgo físico o psíquico para los menores. En relación con este extremo, la Sala considera que La prueba es débil en tanto se concentra en un periodo corto de tiempo coincidente con la ruptura, no exenta de conflicto, de la relación de pareja, no hay denuncia alguna, ni anterior ni posterior, el padre ha podido comunicarse con sus hijos sin que se haya aportado prueba de perjuicio para los menores derivada de dichas comunicaciones. En definitiva, queda acreditada la existencia de una relación muy conflictiva entre la pareja pero no existe prueba suficiente que acredite la existencia de perjuicio para los menores en las comunicaciones con su padre.

45. Aunque los supuestos de violencia doméstica sean subsumibles en el marco del artículo 13 b) del texto convencional y la realidad práctica evidencia un aumento de los supuestos que vinculan ambas situaciones, un análisis de práctica judicial pone de relieve que en pocas ocasiones es admitida esta alegación. La falta de prueba constituye el principal motivo por el que la misma no es acogida por nuestros tribunales ${ }^{67}$. Esta "debilidad" o falta de prueba se deriva, de un lado, porque se ha centrado en acreditar la violencia doméstica que, como en el supuesto que analizamos, era el fundamento sobre el que se sustenta la excepción de grave riesgo para los menores invocada por la apelante. De otro lado, puede ser fruto de la urgencia y rapidez que caracteriza el procedimiento articulado en la LEC. Sin embargo, la tutela del interés superior del menor requiere que el retorno no suponga una solución automática. En la valoración de la excepción planteada la urgencia y rapidez del proceso harán necesaria la participación y cooperación de autoridades y la intervención en la prueba del órgano judicial en los términos del artículo 778 LEC.

\section{La prueba en el marco del proceso de restitución}

46. Las situaciones de violencia doméstica, familiar o de género entrañan una dificultad probatoria peculiar al ser situaciones que se producen en un entorno de intimidad familiar y, además, por las

\footnotetext{
${ }^{64}$ M.J. CAÑAda LoRENZO, "La incidencia de la Violencia de Género en la sustracción internacional de menores (...)”, cit ,p. 3.

${ }^{65}$ Véase apartado 2.I.52 de la Guía de Buenas Prácticas.

${ }^{66}$ SSAP de Granada 152/2017, de 21 de abril (ROJ 486/2017) y de Las Palmas 436/2016 de 25 de julio (ROJ 2345/2016).

${ }^{67}$ Vid. SAP de A Coruña de 5 julio de 2019 (EDJ 2019/660566).
} 
propias características de las víctimas de violencia de género. A ellas se añaden las derivadas de la internacionalidad del supuesto, relativas a los condicionantes de su estancia en el extranjero, las dificultades para buscar protección y desenvolverse en un país distinto al de su nacionalidad. La sentencia dictada por la Audiencia Provincial de Barcelona es una de tantas dictadas en nuestro país en las que, por falta de prueba, no se admite la excepción de grave riesgo derivada de una situación de violencia doméstica frente a la solicitud de restitución de los menores trasladados ilícitamente ${ }^{68}$.

47. Ahora bien, estando acreditada la existencia de una relación conyugal conflictiva, la relación entre esta y la posibilidad de que los menores puedan sufrir daños psíquicos o físicos hubiera aconsejado adoptar medidas o asegurarse que en el Estado de la residencia habitual se adoptasen medidas destinadas a evitar que el mismo se produjera. Como señala AsTRAY CHACón resumiendo los aspectos más relevantes del Proyecto de guía de buenas prácticas sobre el artículo 13 b) CH80, debe tenerse constancia de la relación entre la violencia conyugal y el maltrato infantil y tener en cuenta que el grave riesgo futuro no requiere necesariamente la prueba de la violencia infligida al menor, que puede estar en peligro por la correlación entre ambas violencias ${ }^{69}$. En este marco, también debemos tener en cuenta que encontrándonos ante un proceso de restitución, por su propia naturaleza no dispositiva, si bien solo serán admisibles aquellas pruebas pertinentes para decidir sobre la licitud o ilicitud del traslado o la concurrencia de las excepciones que fueran oponibles y las medidas a adoptar, el juez, de oficio o a instancia de parte o del Ministerio Fiscal, puede recabar los informes que estime pertinentes ${ }^{70}$.

48. En este ámbito, la audiencia del menor trasladado ilícitamente adquiere especial relevancia. En línea con lo dispuesto en los artículos 12, 13 y 20 CH 80 y 11 del Reglamento 2201/03, el párrafo octavo del artículo 778 quinquies de la LEC dispone que, antes de adoptar cualquier decisión relativa a la procedencia o improcedencia del menor o su retorno del lugar de procedencia, el juez, en cualquier momento del proceso y en presencia del Ministerio Fiscal, oirá separadamente al menor, a menos que la audiencia de este no se considere conveniente, atendiendo a su edad o a su grado de madurez, lo cual se hará constar en resolución motivada. Con ello no se trata de decidir acerca del fondo de la custodia sino que la audiencia del menor en el proceso de restitución abordará, entre otros aspectos, conocer la opinión de los menores ante el traslado, su entorno e integración así como sus relaciones con sus progenitores.

49. A la vista de la decisión adoptada por la Audiencia Provincial, los menores, de tres y seis años de edad, no han sido oídos por el tribunal. Esta circunstancia en nada favorece la decisión adoptada. Ciertamente, conforme a las disposiciones citadas en el párrafo anterior la audiencia del menor no puede ser considerada obligatoria en todos los supuestos, debiendo atender el tribunal a la edad del menor y a su grado de madurez. No obstante, la configuración del derecho a ser oído como un derecho fundamental de los menores consagrado en los textos internacionales ${ }^{71}$ y en la Ley Orgánica de protección jurídica del menor $^{72}$ se traduce en una obligación cuya denegación debe constituir una excepción que, en todo caso, ha de justificarse o motivarse ${ }^{73}$.

50. No habiendo sido acreditada la concurrencia de la excepción de grave riesgo, conforme a lo manifestado por la Sala, es innecesario valorar la disponibilidad de medidas de protección adecuadas en el Estado de residencia habitual del menor, en los términos del artículo 11.4 Reglamento 2201/0374.

${ }^{6}$ Entre otras, la SAP436/2016, de la Audiencia Provincial de Las Palmas de 25 de julio (ROJ:SAP GC 2345/201); SAP Murcia 437/2016, de 14 de julio ( ROJ: SAP MU 1834/2016) acuerda el retorno de los menores a Holanda porque estima acreditadas discrepancias entre los progenitores y situación de intolerancia entre los mismos, pero no situación de riesgo de exposición del menor a un peligro físico o psíquico; SAP Asturias ( ROJ: SAP O 863/2017) de fecha 15 de marzo de 2017.

${ }^{69}$ M. P. Astray Chacón, "Las sombras del proceso de restitución del menor. (...)" cit, p. 62.

${ }^{70}$ M. P. Astray Chacón, "Las sombras del proceso de restitución del menor. (...)” cit, p. 31.

${ }^{71}$ Vid. artículo 24, apartado 1, de la Carta de los Derechos Fundamentales de la Unión Europea; los artículos 9 y 12 de la Convención de las Naciones Unidas sobre los Derechos del Niño.

${ }^{72}$ Vid. artículo 9 de la Ley Orgánica 1/1996, de 15 de enero, de Protección Jurídica del Menor.

${ }^{73}$ M. P. Astray Chacón, "Las sombras del proceso de restitución del menor. (...)” cit, p. 37.

${ }^{74}$ Vid. la sentencia de la Audiencia Provincial de A Coruña, de 5 de julio de 2019, nº 262/2019, (ECLI: ES:APC:2019:1546). 
Este precepto prevé que, los órganos jurisdiccionales de un Estado miembro no podrán denegar la restitución de un menor basándose en lo dispuesto en la letra b) del art. 13 del CH 80 si se demuestra que se han adoptado «medidas adecuadas para garantizar la protección del menor tras su restitución». Así, la SAP de Málaga de 30 de abril de 2015, acordó la restitución del menor porque el Estado requirente había adoptado medidas de protección ${ }^{75}$. Sin embargo, en otra sentencia de 11 de septiembre de 2007 denegó la restitución porque no se habían adoptado tales medidas ${ }^{76}$. Con ello, el Reglamento 2210/2003 trata de evitar una aplicación del texto convencional que permita "legalizar" los secuestros internacionales de menores en detrimento de la confianza mutua y las normas de competencia que establecen las disposiciones europeas ${ }^{77}$. Las críticas, por promover el automatismo de decisiones de restitución en los denominados supuestos de retorno seguro, se justificaban por considerar que no debía estar obligada la restitución una vez se había acreditado la excepción de grave riesgo prevista en el texto convencional.

51. En cambio, aunque menos numerosas, algunas decisiones de nuestros tribunales admiten la excepción de grave riesgo ${ }^{78}$. La SAP de Guipúzcoa de 5 de marzo de 2020 es una de ellas ${ }^{79}$, tras la valoración de la prueba concluye la no restitución del menor porque "en este caso que nos ocupa se da la circunstancia de que de la prueba practicada en el procedimiento han resultado acreditados los hechos reseñados por la Juez a quo en su resolución, pues, aun cuando se da la circunstancia de que se ha sostenido por parte tanto del Ministerio Fiscal, como de D. Eladio, que tales hechos no han quedado acreditados, por cuanto se trata de hechos que tan solo han sido puestos de manifiesto por la demandada en sus declaraciones, sin embargo no puede aceptarse en modo alguno tal alegación, por cuanto que ciertamente los mismos se encuentran corroborados por los informes obrantes en las actuaciones, en los que no sólo se expone con toda claridad que el relato efectuado por $D^{a}$. Florinda es perfectamente creíble en todos sus extremos, sino que, además, los mismos ponen de manifiesto los sintomas que la misma presentaba a su llegada a este país y que permiten apreciar que se encontraba asustada, angustiada, desconfiada insegura y deprimida, con pérdida de autoestima, padeciendo insomnio, así como falta de apetito y de energía, síntomas que dotan de credibilidad al relato por ella verificado de los acontecimientos vividos y que en la actualidad va superando positivamente, habiéndose mostrado como una mujer amable, respetuosa, colaboradora, con capacidad de resiliencia, y que busca los aspectos positivos a su situación, a fin de adaptarse a ella y de lograr un futuro mejor para ella y su hijo.

Esos mismos informes se pronuncian en relación al menor Higinio y señalan, por una parte, que el pequeño, cuando llegó a este país, se mostraba esquivo con la mirada, no mantenía contacto visual y no prestaba atención cuando se le llamaba por su nombre, actitud esta que también su madre puso de manifiesto en las extensas alegaciones que efectuó en apoyo a su solicitud de protección, cuando indicó que su hijo llegó muy afectado por el trato que le había dado su padre y que "no miraba a los ojos a nadie, ni a mi, no respondía cuando lo llamaban por su nombre" y que "estaba muy nervioso e hiperactivo", y, por otra parte, que en el colegio presentaba un claro retraso en el desarrollo del lenguaje, extremo este también apuntado por su madre, que inicialmente se relacionaba con sus compañeros a través de la violencia y que no se relacionaba con otros niños, no demandando la compañia de sus iguales y tendiendo a jugar solo, en tanto que, en la actualidad y transcurrido un cierto tiempo, se observa en él una mejoría en cuanto al contacto visual, dado que se muestra más confiado, seguro y tranquilo, así como contento, en tanto que en clase ha mejorado también en cuanto a la interacción con los otros niños. Es, por todo ello, por lo que no puede tomarse en consideración la alegación que D. Eladio efectúa en su escrito de recurso en el sentido de que no se ha practicado al niño ningún examen psicológico en orden a determinar su estado, para a continuación señalar que, dada su edad, no procedería verificársele examen alguno, por cuanto que, precisamente por la corta edad del niño, lo que resulta fundamental son los informes que han emitido

\footnotetext{
${ }^{75}$ SAP Málaga 243/2015, de 30 de abril (ROJ: SAP MA 2349/2015); 588/2012 de 13 de noviembre.

${ }^{76}$ SAP de Málaga 463/2007 de 11 de septiembre (ROJ: SAP MA 2052/2007).

77 A. L. Calvo Caravaca/J Carrascosa González, "Sustracción internacional de menores: una visión general", cit.

${ }^{78}$ Entre otras, las sentencias de la AP de Barcelona de 12 junio de 2020 (ECLI: ES:APB:2020:4886) SAP Guipúzcoa de 5 marzo de 2020 (ECLI: ES:APSS:2020:1496); de Madrid de 21 de marzo de 2012, (ECLI:ES:APM:2012:4853A), y en el AAP de Cádiz de 22 de febrero de 2011, (ECLI:ES:APCA:2011:30A).

79 SAP Guipúzcoa de 5 marzo de 2020 (EDJ 2020/826643).
} 
en relación a él aquellas personas que se han ocupado del mismo y de su madre y que, por ese motivo, han constatado su conducta y sus reacciones en los primeros meses, tras llegar a este país, siendo asimismo importante reseñar que, al principio, el niño se hallaba muy inquieto cuando, en el colegio, se separaba de su madre, lo que evidencia el estrecho vinculo afectivo que media entre ambos y el hecho de que de ninguna manera a ella le puede ser atribuida esa actitud inicial de su hijo, que ponía de manifiesto, como se reseña en tales informes, una sintomatología propia de un pequeño que ha podido ser objeto de un maltrato.

\section{Las medidas de ejecución destinadas a garantizar el retorno del menor}

52. La ejecución de la orden de restitución o retorno del menor sustraído no solo integra el contenido del derecho a la tutela judicial efectiva sino, especialmente, su vulneración puede determinar una violación de los derechos de los menores ${ }^{80}$. Por ello, la adopción de medidas destinadas a garantizar su ejecución adquieren especial relevancia, siendo uno de los aspectos destacados en la Guía de Buenas Prácticas del CH80. En ella se promueve la necesidad de que la decisión de retorno establezca detalladamente la forma en que ha de ejecutarse la decisión de retorno del menor sustraído ilícitamente ${ }^{81}$. En esta línea, el apartado noveno del artículo 778 quinquies LEC dispone que la resolución que acuerde la restitución del menor o su retorno establecerá detalladamente la forma y el plazo de ejecución, pudiendo adoptar las medidas necesarias para evitar un nuevo traslado o retención ilícito del menor tras la notificación de la sentencia. De otro lado, el apartado decimotercero del precepto citado incorpora algunas medidas destinadas a asegurar la ejecución de la decisión relacionadas con la actuación de la Autoridad central, con la intervención de servicios sociales y con las Fuerzas y Cuerpos de Seguridad.

53. El fallo de la sentencia dictada por la Audiencia, junto a la desestimación del recurso de apelación y confirmación de la sentencia apelada, ordenando la restitución del menor, estima parcialmente la impugnación del recurso de apelación que plantea la representación del Sr. Gil, demandante en la instancia, ahora parte apelada. En particular, la estimación se refiere a las medidas de ejecución que se deben adoptar para hacer efectiva la orden de restitución de los menores al Estado de su residencia habitual anterior al traslado.

54. El amplio margen de actuación del que goza el tribunal en relación con la ejecución del retorno de los menores justifica las medidas adoptadas en el fundamento sexto de la sentencia dictada por la Sala. Conforme al artículo 236-3 Cc catalán ${ }^{82}$ la sentencia de apelación determina cómo ha de llevarse a cabo la restitución de los menores a Edimburgo ${ }^{83}$. Teniendo en cuenta el tiempo transcurrido desde que se produjo el traslado y que desde entonces los menores se encuentran al cuidado de la madre, la Sala ordena que sea esta quien se desplace con los menores a Edimburgo en el plazo de quince días. Además, mostrando una vez más la interrelación a la que hemos hecho referencia entre el proceso de restitución y el proceso sobre el fondo del asunto, la Sala manifiesta que, durante su estancia podrá presentar la demanda ante los Tribunales competentes o puede ser que el padre plantee el procedimiento correspondiendo a los Tribunales del Estado de la residencia habitual fijar las medidas de guarda y custodia así como las pautas de comunicación que estime oportunas. Los gastos de viaje corresponderán a la madre, conforme a lo dispuesto en el artículo 778 quinquies 10 LEC.

${ }^{80}$ S. Álvarez GonzÁlez, "Desplazamiento de menores dentro de la UE. Supresión del exequátur y derechos del niño a ser oído", Diario La Ley, núm. 7578, 28 de febrero de 2011.

${ }^{81}$ Vid. aptdo 6.7 de la Guía de Buenas prácticas

${ }^{82}$ Artículo 236-3. Intervención judicial. 1. La autoridad judicial, en cualquier procedimiento, puede adoptar las medidas que estime necesarias para evitar cualquier perjuicio personal o patrimonial a los hijos en potestad. A tal efecto, puede limitar las facultades de los progenitores, exigirles la prestación de garantías e, incluso, nombrar a un administrador judicial. 2. La autoridad judicial puede adoptar las medidas a que se refiere el apartado 1 de oficio o a instancia de los propios hijos, de los progenitores, aunque no tengan el ejercicio de la potestad, de los demás parientes de los hijos hasta el cuarto grado por consanguinidad o segundo por afinidad y del ministerio fiscal.

${ }^{83}$ SAP de Barcelona de 3 de octubre de 2017; SAP Navarra de 3 octubre de 2018 (EDJ 2018/662709). 
55. Alternativamente, si la medida especificada en el apartado anterior no se cumpliera, la Sala acuerda que la madre entregue a los niños con la documentación de identificación necesaria a su padre para ser trasladados a Edimburgo de forma inmediata, debiendo adoptarse las medidas pertinentes para que la entrega se haga efectiva en España y para permitir el viaje de los niños, incluyendo el alzamiento de las medidas de prohibición de salida del territorio nacional si las hubiere. Para terminar, la Sala recomienda, siguiendo las pautas de la Conferencia de La Haya que los progenitores se sometan a un procedimiento de mediación en los términos del artículo 778 quinquies LEC para acordar los términos de la restitución.

56. La primera cuestión que plantean las medidas adoptadas se refiera a su calificación, naturaleza y fundamentación jurídica. En el proceso de restitución inmediata del menor, las medidas tendentes a garantizar la eficacia y rapidez del retorno adquieren especial relevancia. En este contexto, junto a medidas cautelares y provisionales que responden a una finalidad preventiva y tratan de evitar o impedir el riesgo de traslados ilícitos (artículos 103 y 158Cc), se encuentran aquellas otras que tienen por objeto garantizar la efectividad, seguridad y ejecución de la decisión adoptada. En esta línea, la sentencia de apelación tiene un contenido amplio e incluye datos claros relacionados con la forma en la que deberá procederse a la restitución y, atendiendo a las circunstancias del supuesto especifica vías alternativas tendentes a garantizar la tutela de los menores y su inmediata restitución. Entre estas medidas, la mediación se propone como mecanismo para facilitar la ejecución de la decisión de retorno ${ }^{84}$.

\section{A modo de conclusión}

57. Las circunstancias en las que actualmente se desarrollan algunos supuestos de sustracción internacional de menores evidencian su vinculación con situaciones de violencia doméstica o de género. En tales casos, la excepción de grave riesgo para el menor como consecuencia de la restitución o retorno inmediato debe ser acreditada por la persona que la alega, esto es, quien ha llevado a cabo el traslado ilícito. La práctica judicial española evidencia las dificultades que suscita aquella realidad. La prueba de estas situaciones, que ya resulta compleja por las particularidades que implica, se incrementa en supuestos vinculados a distintos Estados. Si bien su valoración corresponde al tribunal que conoce del proceso de restitución, es imprescindible en este ámbito la cooperación de autoridades. La tutela del interés de los menores, auténticas víctimas de los traslados ilícitos, debe guiar la actuación de las autoridades, judiciales y administrativas, que intervienen así como la labor de las partes en el proceso. La adecuación de las previsiones normativas a las particularidades de cada caso en aras a la tutela del interés superior del menor debe guiar las soluciones frente a los traslados ilícitos de menores cuando concurre violencia de género, doméstica o familiar.

${ }^{84}$ Otras decisiones también promueven la mediación. Vid, a modo de ejemplo, la SAP Navarra de 3 octubre de 2018 (EDJ 2018/662709). Sobre la mediación en el ámbito de la sustracción internacional de menores, vid. C. ArCÁrraga Monzonís/P. QuinzÁ Redondo, "Sustracción internacional de menores y Convenio de La Haya de 1980. Comentario a la Sentencia de la Audiencia Provincial de Las Palmas (Sección 3ª) núm. 377/2017, de 29 de junio”, CDT (octubre 2018), vol. 10, núm. 2, pp. 795-801; A. Fernández Pérez, "La mediación en la sustracción internacional de menores desde la perspectiva europea", en V. Rojas Amandi (Coord.) Desarrollos modernos del Derecho internacional privado: Libro Homenaje al Dr. Leonel Pereznieto Castro, 2017, pp. 317-348; P. Orejudo Prieto De Los Mozos, "Competencia judicial internacional y contenido de los acuerdos de mediación en la sustracción internacional de menores", en C. Azcárraga Monzonís y P. Quinzá Redondo (Eds): Tratado de Mediación, Tomo III. Mediación en conflictos de familia, 2017; N. GonZÁlez Martín, "Sustracción internacional parental de menores y mediación. Dos casos para la reflexión: México (amparo directo en revisión 903/2014) y los Estados Unidos de América (Lozano v. Montoya Álvarez)”, www. reei.org, 2015. 